\title{
Crenças de professores do Ensino Fundamental sobre leitura de textos literários
}

\author{
Beliefs of Elementary School teachers about reading literary texts \\ Creencias de los profesores de Escuela Primaria sobre la lectura de textos literarios
}

\section{Resumo}

As crenças dos professores sobre leitura de textos passam pelo processo de formação acadêmica, pelas diretrizes e documentos, que orientam, normatizam e definem os conhecimentos essenciais para o processo de ensino e aprendizado no país, além das suas experiências e práticas de sala de aula. O presente trabalho tem a intenção de investigar quais as crenças dos professores do Ensino Fundamental de escolas públicas de Santa Maria, no Rio Grande do Sul, sobre leitura de textos literários. A pesquisa é de abordagem qualitativa, pautada a partir da análise de questionários destinados aos professores, para isso, a caracterização da pesquisa é através do método de Análise Exploratória, da Análise Crítica do Discurso fundamentada pelo livro Discurso e Mudança Social de Norman Fairclough e da Gramática Sistêmicofuncional da Língua Portuguesa. Com a conclusão da pesquisa, após a análise das respostas, todos os professores participantes acreditam que a leitura de textos literários é uma prática importante em sala de aula.

Palavras-chave: Ensino; Literatura; Leitura.

\begin{abstract}
Teachers' beliefs about reading texts go through the academic training process, through guidelines and documents, which guide, standardize and define essential knowledge for the teaching and learning process in the country, in addition to their experiences and classroom practices. The present work intends to investigate the beliefs of elementary school teachers from public schools in Santa Maria, in Rio Grande do Sul, about reading literary texts. The research has a qualitative approach, based on the analysis of questionnaires intended for teachers, for this, the characterization of the research is through the method of Exploratory Analysis, Critical Discourse Analysis based on the book Discourse and Social Change by Norman Fairclough and the Systemic-functional grammar of the Portuguese language. The conclusion of the research, after analyzing the answers, all participating teachers believe that reading literary texts is an important practice in the classroom.
\end{abstract}

Keywords: Teaching; Literature; Reading.

\section{Resumen}

Las creencias de los docentes sobre la lectura de textos pasan por el proceso de formación académica, a través de lineamientos y documentos, que orientan, estandarizan y definen conocimientos esenciales para el proceso de enseñanza y aprendizaje en el país, además de sus experiencias y prácticas de aula. El presente trabajo tiene como objetivo investigar las creencias de los maestros de primaria de las escuelas públicas de Santa María, en Rio Grande do Sul, sobre la lectura de textos literarios. La investigación tiene un enfoque cualitativo, basado en el análisis de cuestionarios destinados a los docentes, para ello, la caracterización de la investigación es a través del método de Análisis Exploratorio, Análisis Crítico del Discurso basado en el libro Discurso y Cambio Social de Norman Fairclough y la Sistémica-gramática funcional de la lengua portuguesa. Con la conclusión de la investigación, luego de analizar los cuestionarios, todos los profesores participantes creen que la lectura de textos literarios es una práctica importante en el aula.

Palabras clave: Enseño; Literatura; Lectura.

\section{Introdução}

O educador e escritor Rubem Alves desejava um novo tipo de professor, aquele que não é capaz de ensinar, mas de provocar espantos nos alunos, pois o objetivo da educação não é ensinar coisas, porque o conhecimento já está na internet ao 
alcance das mãos, nos celulares, tablets e computadores, nos jornais, nas revistas e, tradicionalmente, nos livros. Segundo ele, o grande objetivo da educação é ensinar a pensar e criar curiosidade (Alves, 2011) e a leitura ainda é uma das formas mais importantes de refletir sobre o mundo e motivar o interesse pelo conhecimento.

O estímulo à leitura é fundamental para despertar a curiosidade e o pensamento dos alunos, pois compreender um texto, seja verbal ou não verbal, não é uma simples codificação de palavras ou imagens, é fazê-lo ter sentido e importância para o leitor. Soares (2003) diz que ler "é um conjunto de habilidades e comportamentos que se estendem desde simplesmente decodificar sílabas ou palavras até ler Grande Sertão Veredas de Guimarães Rosa... uma pessoa pode ser capaz de ler um bilhete, ou uma história em quadrinhos, e não ser capaz de ler um romance”, de acordo com a simplicidade ou complexidade da leitura, ou seja, uma linguagem simples é facilmente decodificada por qualquer leitor, no entanto, linguagens mais complexas demandam mais dedicação e conhecimento do leitor.

A leitura de textos literários inicia no Ensino Fundamental e perpassa todo o Ensino Médio, pois os alunos, desde os primeiros anos escolares, são apresentados aos poemas, aos contos, às fábulas, ao teatro e, mais tarde, às novelas e aos romances. Assim sendo, estão em contato, muito cedo, com uma linguagem literária, mais complexa, expressa pela palavra que se constrói artisticamente, plurissignificativa e subjetiva. Por mais que o texto literário se aproxime de outros textos escritos, ele apresenta certas características, capazes de provocar um estranhamento decorrente de sua elaboração particular. Lajolo (1981) diz que “a linguagem parece tornar-se literária quando seu uso instaura um universo, um espaço de interação de subjetividade (autor e leitor) que escapa ao imediatismo, à predictibilidade e ao estereótipo das situações e usos da linguagem que configuram a vida cotidiana", por isso, consequentemente, se torna mais difícil de ser compreendida.

A Base Nacional Comum Curricular (BNCC), documento normativo para os professores da Educação Básica, que define o conjunto de aprendizagens essenciais para os alunos, também atribui competências específicas ao aluno, que deverá ser capaz de

ler, escutar e produzir textos orais, escritos e multissemióticos que circulam em diferentes campos de atuação e mídias, com compreensão, autonomia, fluência e criticidade, de modo a se expressar e partilhar informações, experiências, ideias e sentimentos, e continuar aprendendo, além de vivenciar experiências significativas com práticas de linguagem em diferentes mídias (impressa, digital, analógica), situadas em campos de atuação social diversos, vinculados com o enriquecimento cultural próprio, as práticas cidadãs, o trabalho e a continuação dos estudos (BNCC, 2018, p. 484).

Da mesma forma que os antigos PCNs, a atual BNCC exige a construção de um aluno-leitor autônomo e crítico de sua realidade, para que possa interagir, em um processo contínuo de leitura e aprendizado, com a sociedade e cumprir seu papel de cidadão.

Assim sendo, o presente trabalho, que é parte integrante do projeto de pesquisa do Mestrado em Ensino de Humanidades e Linguagens da UFN, tem como objetivo geral investigar as crenças sobre leitura de textos literários de professores de Ensino Fundamental, do $6^{\circ}$ ano até o $9^{\circ}$ ano, do município de Santa Maria, Rio Grande do Sul. Além disso, tem alguns objetivos específico que servirão de suporte para o objetivo geral, são eles: identificar as concepções de leitura de textos literários dos professores, descrever as concepções do nível da educação, para a emersão de categorias de crenças e discutir as implicações dessas crenças para o ensino de literatura na Educação básica.

\section{Metodologia}

A pesquisa é de abordagem qualitativa e de natureza descritiva, com a utilização do método da Análise Crítica do Discurso, contemplando suas três dimensões analíticas: análise do texto, análise da prática discursiva e análise da prática social, além da apreciação pela Gramática Sistêmico-funcional da Língua Portuguesa. 
A pesquisa de abordagem qualitativa dedica-se ao estudo de fenômenos que envolvem os seres humanos e suas relações sociais, estabelecidas de diversas formas, por isso o pesquisador faz uma análise sobre uma perspectiva integrada, a partir das pessoas envolvidas em um determinado fenômeno e observando o que é relevante. Neste tipo de abordagem os dados são recolhidos e analisados para que se entenda possíveis hipóteses pertinentes à pesquisa. Bardin (2016) afirma que a abordagem qualitativa é um

procedimento mais intuitivo, mas também mais maleável e mais adaptável, a índices não previstos, ou à evolução das hipóteses. Este tipo de análise, deve ser então utilizado nas fases de lançamento das hipóteses, já que permite sugerir possíveis relações entre um índice da mensagem e uma ou várias variáveis do locutor (ou da situação de comunicação) (Bardin, 2016, p.115)

Portanto, a abordagem qualitativa pode partir de questões mais amplas, tendo em vista que pode sugerir, ao longo da pesquisa, outras formas de conduzir o estudo. A escolha dessa abordagem se deu pela adequação à pesquisa, pois no entendimento de Bardin (2016) é possível trabalhar "na elaboração das deduções específicas sobre um acontecimento ou uma variável de inferência precisa, e não em inferências gerais", portanto, "pode funcionar sobre corpus reduzidos e estabelecer categorias mais descriminantes".

A pesquisa de natureza descritiva é estabelecida na fase inicial após a coleta dos dados para o estudo, com a intenção de organizar, resumir e descrever informações pertinentes para avançar às análises posteriores. Pode se dizer que é uma fase de reflexão, levantamento de proposições, a partir dos dados que foram levantados na pesquisa, dessa forma, “o objeto de estudo proposto, que definiu a pesquisa como exploratório-descritiva, expõe-se a síntese integradora das soluções que formaram o processo de investigação" (Lima \& Mioto, 2007, p. 43).

No livro Discurso e Mudança Social, ao longo do Capítulo III, Norman Fairclough trata da Teoria Social do Discurso, apresentando uma concepção de discurso e um quadro teórico para a análise do discurso. A abordagem de Fairclough (2001, p. 89) tem o objetivo de "reunir a análise de discurso orientada linguisticamente e o pensamento social e político relevante para o discurso e a linguagem, na forma de um quadro teórico" para ser utilizado na pesquisa social e no estudo da mudança social. Ele apresenta o discurso em três dimensões: como texto, prática discursiva e prática social.

Fairclough usa o termo "discurso", da mesma forma que os linguistas, como "uso de linguagem", "fala" ou “desempenho”. Relembra a tradição de Saussure que desconsidera a fala, por ser individual, intencional e imprevisível, impossibilitando seu estudo, pois guarda em si mesma um sistema social, mas Fairclough (2001, p. 90) argumenta que isso é atacado pelos sociolinguístas, "que afirmam ser o uso de linguagem moldado socialmente e não individualmente”, portanto a fala é formada pelas variáveis sociais, pela relação entre os participantes, pelo tipo de evento e propósito social, etc.

O autor define o discurso quando se faz "o uso de linguagem como forma de prática social”, gerando implicações: uma espécie de ação, quando as pessoas agem sobre o mundo, os outros e o modo de representação; um diálogo entre o discurso, moldado e restringido, e a estrutura social. No entendimento de Fairclough (2001, p. 91), "o discurso é uma prática, não apenas de representação do mundo, mas de significação do mundo, constituindo e construindo o mundo em significado.”, que produz três efeitos: a construção de "identidades sociais", "posições de sujeito" para os "sujeitos” sociais e os tipos de 'eu'; a construção das "relações sociais entre as pessoas"; e a "construção de sistemas de conhecimento e crença". Esses efeitos correspondem a três funções da linguagem: indentitária, como as identidades sociais se estabelecem no discurso, relacional, como as relações sociais entre os participantes do discurso são representadas e negociadas, e ideacional, como os textos significam o mundo. Acrescenta a função textual, de Halliday (1978), como as informações são trazidas para um primeiro plano ou deixadas para um segundo plano, vista como novas, como as partes do texto se ligam e sua relação com o que está fora do texto, a situação social. 
A prática discursiva é constitutiva tanto de maneira convenciona como criativa: contribui para reproduzir a sociedade (identidades sociais, relates sociais, sistemas de conhecimento e crença) como e, mas também contribui para transformála. Por exemplo, as identidades de professores e alunos e as relações entre elas, que estão no centro de um sistema de educação, dependem da consistência e da durabilidade de padrões de fala no interior e no exterior dessas relações para sua reprodução. Porém, elas estão abertas a transformações que podem originar-se parcialmente no discurso: na sala da sala de aula, do parquinho, da sala dos professores, do debate educacional, e assim por diante. (Fairclough, 2001, p. 92)

Por isso é fundamental a relação de diálogo entre o discurso e a estrutura social, para evitar que o discurso se torne somente o reflexo de uma realidade social ou seja representado idealizadamente como fonte do social. Conforme indicado por Fairclough (2001, p. 93) "a constituição discursiva da sociedade não emana de um livre jogo de ideias nas cabeças das pessoas, mas de uma pratica social que está intimamente enraizada em estruturas sociais matérias, concretas, orientando-se para elas.”

As preocupações de Fairclough (2001, p. 94) centram-se no estudo do discurso como prática política, quando estabelece, mantém e transforma as relações de poder nas entidades coletivas, e como prática ideológica, quando "constitui, naturaliza, mantém e transforma os significados do mundo de posições diversas nas relações de poder". A prática política e a prática ideológica não são independentes, pois uma é gerada pela outra, de forma que o discurso como prática política não é apenas um local de luta ou delimitação de poder, mas também um local que naturaliza as "relações de poder e ideologias particulares e as próprias convenções, e os modos em que se articulam são um foco de luta”. A concepção do discurso para Flairclough é representada em três dimensões: o discurso como texto, prática discursiva e prática social.

Na dimensão do discurso como texto, sempre se deve tratar do aspecto do texto referindo-se à sua produção e/ou sua interpretação textual. A análise textual pode ser organizada em quatro itens:

'vocabulário', 'gramática', 'coesão' e 'estrutura textual'. Esses itens podem ser imaginados em escala ascendente: o vocabulário trata principalmente das palavras individuais, a gramática das palavras combinadas em orações e frases, a coesão trata da ligação entre orações e frases e a estrutura textual trata das propriedades organizacionais de larga escala dos textos. (Fairclough, 2001, p. 103)

Esses itens constituem um quadro para a análise textual que abrange aspectos de sua produção e interpretação como também as propriedades formais dos textos. Conforme indicado por Fairclough, o vocabulário pode ser investigado de diversas formas, não o limitando ao sentido restrito do dicionário, mas explorando as palavras alternativas, suas significações políticas, ideológicas e metafóricas. A gramática deve ser vista pela sua unidade principal que é a oração, desde as mais simples até as mais complexas, observando suas multifuncionalidades, combinação de significados ideacionais, interpessoais e textuais. A coesão representa a ligação entre as orações, que por sua vez, são ligados às outras unidades do texto. A estrutura textual constrói a arquitetura e aspectos que planejam o tipo de texto.

A prática discursiva envolve processos de produção, distribuição e consumo textual, e a natureza desses processos varia entre diferentes tipos de discurso de acordo com fatores sociais. No entendimento de Fairclough "os processos de produção e interpretação são socialmente restringidos num sentido duplo”, pelos recursos disponíveis das pessoas e pela natureza da pratica social da qual fazem parte. O contexto é importante à prática discursiva, para reduzir a ambivalência dos sentidos expostos, mas Fairclough argumenta que "antes que se possa recorrer ao contexto de situação, ou mesmo ao contexto sequencial, para interpretar a força de um enunciado, deve-se ter chegado a uma interpretação sobre qual é o contexto de situação", pois seria possível entender melhor a prática discursiva, se compreendesse as inter-relações das pessoas como uma espécie de "mapa mental da ordem social".

Fairclough (2001, p. 116) apresenta o conceito de discurso como prática social, fazendo uma relação entre ideologia e poder, situando o discurso em uma concepção de poder e luta hegemônica, para isso utiliza-se das reflexões de Marx, Althusser e Gramsci, "que oferecem uma teoria rica para a investigação do discurso como forma de prática social." 
As três importantes afirmações que servem de base para Fairclough são: que a ideologia existe materialmente nas práticas institucionais, que a ideologia interpela os sujeitos e que os aparelhos ideológicos do estado são delimitadores nas lutas de classe. No seu entendimento

as ideologias são significações/construções da realidade (o mundo físico, as relações sociais, as identidades sociais) que são construídas em várias dimensões das formas/sentidos das práticas discursivas e que contribuem para a produção, a reprodução ou a transformação das relações de dominação.(Fairclough, 2001, p.117)

As ideologias são eficazes, pois estão dentro das práticas discursivas, se naturalizando e se tornando senso comum, mas isso não é estável, pois pode ocorrer uma transformação, apontando uma luta ideológica, com outras práticas discursivas reestruturando o contexto e mudando as relações de dominação. Assim sendo, Farclough (2001, p. 119) afirma que "as práticas discursivas são investidas ideologicamente a medida que incorporam significações que contribuem para manter ou reestruturar as relações de poder.”. Quase no final do capítulo, Fairclough admite que a evolução das relações de poder permite um foco particular sobre a mudança discursiva gerando a hegemonia, que é representada pela liderança dos domínios econômicos, políticos, culturais e ideológicos de uma sociedade.

A teoria linguística sistêmico-funcional, concebida por Michael Halliday, analisada na Introdução à Gramática Sistêmico-funcional da Língua Portuguesa, vê a língua de duas formas, uma voltada para sistemas linguísticos interligados (semânticos, léxico-gramaticais ou fonológicos e grafológico), que servem para dar sentido às coisas do mundo, e outra voltada à função da estrutura gramatical e seu sentido dentro do texto. No entendimento de Fuzer \& Cabral (2014; apud Webster 2009, p. 7), "a teoria sistêmico-funcional busca identificar as estruturas de linguagem específica que contribuem para o significado de um texto", assim sendo, a teoria se propõem a demonstrar "como e por que um texto significa o que significa."

No primeiro capítulo da Introdução à Gramática Sistêmico-funcional da Língua Portuguesa, as autoras atentam para os conceitos básicos de linguagem, texto e contexto. Definem a linguagem como "um recurso para fazer e trocar significados, utilizada no meio social de modo que o indivíduo possa desempenhar papéis sociais", o texto como "uma entidade semântica, isto é, um constructo de significados e, ao mesmo tempo, uma troca social de significados" (Fuzer \& Cabral, 2014, p. 21), que se insere em dois contextos: de situação, que é o ambiente imediato que o texto está funcionando, e de cultura, que são os ambientes mais amplos (países, grupos étnicos, família, escola, igreja, etc.). No contexto de situação existem três variáveis: o campo, que são as atividades realizadas pelos participantes (ação social e objetivos específicos), as relações, que representam o grau de envolvimento entre participantes (hierárquica ou não, mínima, média ou máxima), e o modo, que "refere-se à função que a linguagem exerce e ao veículo utilizado naquela situação ou, ainda, ao que os participantes esperam que a linguagem faça por eles em determinada situação" (Fuzer \& Cabral, 2014, p. 30). Na sequência, fazem uma análise das variáveis do contexto de situação, que estão relacionadas às funções ou aos propósitos que a linguagem desempenha, definidas por Halliday (1944) como "metafunções". A metafunção ideacional apresenta a compreensão e representação do meio (realizada pela função experiencial, que constrói um modelo de representação de mundo, e lógica, que são as combinações de grupos lexicais e oracionais, analisada pelo sistema conhecido como transitividade). A metafunção interpessoal apresenta o modo como os participantes estabelecem relações uns com os outros (informações de tempo, modalidade e polaridade), constituídas pela oração. Por último, a metafunção textual apresenta a organização da mensagem, que é constituída de um Tema, ponto de partida da mensagem (localiza e orienta a oração) seguido de um Rema, informação trazida pelo Tema .

No segundo capítulo, Metafunção experiencial - oração como representação, as autoras principiam afirmando que o componente experiencial da metafunção ideacional da linguagem representa a experiência do indivíduo em seu mundo material ou interior, o mundo exterior ou da consciência, percepção, emoção e imaginação. A partir disso, estudam-se o aspectos léxicogramaticais que revelam experiências com a linguagem, que se relacionam com o mundo - o campo, para isso, é importante 
entender o sistema de transitividade, que consiste na descrição de toda a oração, composta de: processos (eventos que constituem experiências, atividades humanas, aspectos do mundo físico, mental e social, que são identificados nos verbos) participantes (entidades envolvidas, pessoas, seres, coisa, etc., que são identificados nos substantivos) e circunstâncias (o modo, o tempo, o lugar, a causa, etc., que são identificados nos advérbio). As relações entre processo, participantes e circunstância forma uma figura.

Há três tipos principais de processos nas orações, que representam as experiências humanas: material (experiências externas, ações e eventos, ligadas à ideia de fazer, construir, acontecer, etc.), mental (experiências internas, às lembranças, às reações, às reflexões, aos estados de espírito, identificadas na ideia de lembrar, pensar, imaginar, gostar, querer, etc.), relacional (representação das relações, identificação e caracterização, atribuídas ao ser, estar, parecer, ter, etc.). Além disso, existem outros três processos nas orações, entre os anteriores: comportamental (entre o material e o mental estão as atividades psicológicas ou fisiológicas, como dormir, bocejar, tossir, dançar), verbal (entre o mental e o relacional, a representação dos dizeres, como responder, afirmar, dizer) e existencial (entre o relacional e o material, representa a existência do participante, como existir, haver).

No terceiro capítulo, Metafunção interpessoal - oração como troca, estudam-se aspectos léxico-gramaticais que realizam a metafunção interpessoal da linguagem e o sistema de modo. Observam-se as maneiras pelas quais falantes e escritores usam as orações para interagir, os recursos de modalidade e polaridade que recorrem, que estão disponíveis no sistema linguístico, para estabelecerem comunicação no meio social, gerando duas funções semânticas, interações de trocas de informações (proposição) ou de bens e serviços (proposta). O sistema de modo é a parte da oração que desempenha a metafunção interpessoal e estabelece, no nível léxico-gramatical, as proposições e propostas, dessa forma, as orações podem se apresentar de três modos: interrogativo (realizadas através de perguntas), declarativo ou indicativo (podem ser exclamativas e não exclamativas, realizando declarações) e imperativo (indicados por verbos que expressam ordem, realizando comandos). Os componente interpessoais da oração são: o Modo, constituído de Sujeito (grupo nominal ou pronominal, que poder ser omitido ou elíptico) e Finito (grupo verbal, que carrega o tempo, a modalidade e a polaridade) e Resíduo, que é o restante da oração, consiste em três elementos funcionais: Predicador, que é realizado por um grupo verbal menos o operador modal ou temporal, Complemento, que é realizado tipicamente por um grupo nominal, podendo integrar um grupo adjetival, e Adjunto, que é realizado por um grupo adverbial.

Ainda neste capítulo, conceituam-se os termos Polaridade, Modalidade, Modalização e Modulação. A Polaridade está ligada a forma verbal e define-se pela utilização de sentenças positivas ou negativas; a Modalidade está relacionada ao julgamento do sujeito em diferentes graus, sua posição, opinião ou ponto de vista; a Modalização ou Modalidade sistêmica acontece quando existe troca de informações ou conhecimento; e Modulação ou Modalidade deôntica aparece na ocorrência de propostas (ofertas em um grau de inclinação e comandos em um grau de obrigação).

No quarto capítulo, Metafunção textual - oração como mensagem, atenta-se para a oração vista como mensagem em sua estrutura temática, organizando os significados experienciais e interpessoais coerentemente. A estrutura do texto faz parte da comunicação e a GSF divide em dois sistemas que se relacionam: a Estrutura da informação, quando apresenta-se o que é dado e o que é novo, e a Estrutura temática, que envolve as funções Tema e Rema quando o autor coloca em destaque a informação, dá pistas sobre o desenvolvimento ou determina a fluência do texto.

Tanto o livro Discurso e Mudança Social, especificamente o Capítulo III, de Norman Fairclough como a Introdução à Gramática Sistêmico-funcional da Língua Portuguesa de Cristiane Fuzer e Sara Regina Scotta Cabral foram importantes para análise dos dados da pesquisa.

A coleta de dados foi realizada, após a apreciação e liberação do Comitê de Ética da Universidade Franciscana, a autorização da Secretaria de Município de Educação e a disponibilização dos e-mails das escolas, pelo envio de questionário a 
todos os professores da rede municipal de Santa Maria, que trabalham com Língua Portuguesa de $6^{\circ}$ até o $9^{\circ}$ ano do Ensino Fundamental, com dois conjuntos de informação: sobre o perfil profissional do participante e sobre as crenças dos professores em relação à leitura de textos literários. O questionário tinha uma folha de rosto com o Termo de Consentimento Livre e Esclarecido e, ao prosseguir com o preenchimento do questionário (que foi enviado como formulário digital, Google forms), o participante concordou com os termos propostos e respondeu as seguintes questões: Qual a sua formação? Em qual rede de Educação Básica você atua? Em quais níveis de ensino você atua? Se você atua nos anos finais do Ensino fundamental, o faz em qual(is) ano(s)? Você trabalha com leitura de textos literários em sala de aula? Você acredita que a leitura de textos literários é uma prática importante em sala de aula? Por quê? Você acredita que, ao longo de sua formação acadêmica, foi capacitado para ensino e prática de leitura de textos literários no Ensino Fundamental? Para você, a leitura de texto literário em sala de aula serve para quê? Na sua percepção, quais competências e habilidades são necessárias para a leitura de textos literários? Quais dificuldades você enfrenta no desenvolvimento de habilidades e competências nos alunos, para que eles leiam textos literários? e Quais estratégias você utiliza para superar as dificuldades no desenvolvimento de competências e habilidades de leitura de textos literários?

O questionário ficou à disposição dos professores de oito de julho de 2021 até trinta de julho de 2021 e somente dez professores responderam às questões. Levou-se também em consideração critérios de inclusão, pois somente poderiam participar da pesquisa os professores com formação em Letras-Licenciatura, atuantes (como regentes) no Ensino fundamental II, com matrícula de servidor efetivo na rede pública municipal de ensino, signatários do Termo de Consentimento Livre e Esclarecido (TCLE) e que responderam as questões dissertativas e como critérios de exclusão, foram retirados da pesquisa os professores que não eram licenciados em Letras, com desvio de função (que não estão em sala de aula como professores regentes), com contrato temporário, não signatários do TCLE ou que não responderam as questões dissertativas. Dos dez professores participantes, somente dois foram excluídos, um porque não ser signatário do TLCE e outro por não responder às questões dissertativas.

\section{Resultados e Discussões}

O universo de análise estabelecido através das respostas de oito professores, embora não seja um número expressivo, apresentou resultados significativos. Quanto às formações acadêmicas, dois são somente licenciados em Letras, dois especialistas, dois mestres, um doutor e um pós-doutor, revelando uma diversidade ampla de níveis de aperfeiçoamento desses profissionais; cinco atuam somente na rede pública e três na rede pública e privada, ao mesmo tempo; todos são professores dos anos finais do Ensino Fundamental; todos trabalham com leitura de textos literários; e acreditam que a leitura de textos literários é uma prática importante em sala de aula.

Os professores também foram questionados se acreditavam que, ao longo de sua formação acadêmica, teriam sido capacitados para ensino e prática de leitura de textos literários no Ensino Fundamental, as respostas se dividiram igualmente, pois quatro acreditam que sim e quatro que não.

Quando questionados por que acreditavam na importância da leitura de textos literários, tendo em vista, inicialmente, que todos concordaram que é uma prática fundamental, as respostas, que fortaleceram essa fundamentação, foram as seguintes: 
Quadro 1 - Você acredita que a leitura de textos literários é uma prática importante em sala de aula? Por quê?

\begin{tabular}{|c|c|}
\hline 1 & $\begin{array}{l}\text { Porque o estudante amplia seus horizontes ao assimilar a visão de mundo do autor. Oferece outros mundos, múltiplas } \\
\text { possibilidades, outras visões. Também ele aprende a estrutura da língua por modelos sólidos e criativos, sem esforço extra, só pelo } \\
\text { ato de ler. Paralelo a isso, amplia o repertório de palavras em seu vocabulário pessoal. Creio que também ajuda na produção e } \\
\text { interpretação de textos autorais. }\end{array}$ \\
\hline 2 & $\begin{array}{l}\text { orque os textos literários são mais ricos em conteúdo e significado, permitindo ao aluno um mergulho na obra. Porém, nem } \\
\text { mpre é possível fazer esse trabalho em aula, com a mediação do professor, o que é muito importante. }\end{array}$ \\
\hline 3 & $\begin{array}{l}\text { A leitura de textos literários permite ao aluno expandir seu vocabulário, expressar suas ideias, interpretar e compreender mais o } \\
\text { seu contexto. }\end{array}$ \\
\hline 4 & $\begin{array}{l}\text { or favorecer não apenas a prática da leitura, como beneficiar a interpretação de mundo e inserir nossos alunos no benefício da } \\
\text { rendizagem. }\end{array}$ \\
\hline 5 & cho que são importantes para os alunos terem contato com esse tipo de texto, o que já não é muito comum fora da escola. \\
\hline 6 & $\begin{array}{l}\text { Creio na relevância do trabalho com textos literários pelo contato com a situação estética da escrita e por serem textos que, devido } \\
\text { às inversões frasais e, em alguns casos, pelo uso de um português arcaico, traz ao aluno maturidade ao trabalhar com a língua } \\
\text { (sintaxe/ortografia/vocabulário), e com a linguagem (semântica/possíveis interpretações). }\end{array}$ \\
\hline 7 & Toda leitura trará benefícios na linguagem, na escrita, no vocabulário, na criatividade, etc. \\
\hline & $\begin{array}{l}\text { faz com que o aluno depare-se com um estilo de escrita que possa propiciar informações e } \\
\text { os demais textos. }\end{array}$ \\
\hline
\end{tabular}

Fonte: Autores (2021).

Ao se justificarem, os professores $(1,2,3,4,6,7$ e 8) se aproximaram quanto as respostas e a relevância para o aspecto do vocabulário e da linguagem nos textos literários, pois identificam-se a repetição das ideias de que "amplia o repertório de palavras em seu vocabulário pessoal”, "os textos literários são mais ricos em conteúdo e significado", é capaz de “expandir seu vocabulário", "a prática da leitura" beneficia " a interpretação de mundo", o aluno amadurece "ao trabalhar com a língua (sintaxe/ortografia/vocabulário), e com a linguagem (semântica/possíveis interpretações)”, “trará benefícios na linguagem, na escrita, no vocabulário, na criatividade" e pode "propiciar informações e conhecimentos diferenciados dos demais textos". Uma crítica nesse sentido, sobre a importância da linguagem, é feita por Fairclough (2001, p. 19) no seu livro, cujo objetivo principal é desenvolver uma abordagem de análise linguística que possa contribuir para esse estudo - "uma abordagem que será útil particularmente para investigar a mudança na linguagem e que será útil em estudos de mudança social e cultural”, dessa forma, o autor corrobora as ideias dos professores, na crença que a aquisição de vocabulário é relevante para a mudança do mundo do leitor.

Embora o questionamento aos professores desperte, obviamente, o interesse no que acreditam sobre a leitura de textos literários, percebe-se a marca de orações mentais cognitivas (1, 5, 6 e 8), por exemplo, “Creio que também ajuda na produção e interpretação de textos autorais", "Acho que são importantes para os alunos terem contato com esse tipo de texto", "Creio na relevância do trabalho com textos literários" e "Acredito que o texto literário", dessa forma, "constituem-se de processos que se referem à consciência do mundo de nossa consciência" (Fuzer \&; Cabral, 2014, p. 54), por isso, as respostas nos conduzem, mais uma vez, a certeza dos professores sobre as práticas de leituras de textos literários em sala de aula.

Quando questionados para que a leitura de texto literário em sala de aula serve, obteve-se as seguintes respostas: 
Quadro 2 - Para você, a leitura de texto literário em sala de aula serve para quê?

\begin{tabular}{|c|c|}
\hline 1 & $\begin{array}{l}\text { Serve para entrar em contato com outros universos, já elaborados, criativos, ficcionais ou não, para apreender um sistema de } \\
\text { linguagem mais elaborado e profundo. Para compreender ao se identificar ou entra em conflito com a personagem, sua própria } \\
\text { existência. Para adquirir vocabulário também. E melhora a capacidade de escrita. }\end{array}$ \\
\hline 2 & $\begin{array}{l}\text { Serve para trabalhar com aspectos ligados à afetividade e vivências dos alunos, compreensão e interpretação, além da ortografia, } \\
\text { pontuação, vocabulário, coerência, coesão. }\end{array}$ \\
\hline 3 & Aperfeiçoar o vocabulário e contextualizar os conhecimentos. \\
\hline 4 & Inserir o aluno no mundo da leitura. \\
\hline 5 & $\begin{array}{l}\text { Sinceramente, eu, ao utilizar esse tipo de texto, objetivo que os alunos desenvolvam a criticidade, a criatividade e que conheçam } \\
\text { algumas obras clássicas. }\end{array}$ \\
\hline 6 & $\begin{array}{l}\text { A leitura de textos literários dá ao aluno mais maturidade linguística, pois exigem mais atenção para formar as possíveis } \\
\text { interpretações. }\end{array}$ \\
\hline 7 & Creio já ter respondido anteriormente \\
\hline 8 & $\begin{array}{l}\text { Além de possibilitar o conhecimento de diversas temáticas sob perspectivas diferentes, pode servir para movimentar saberes } \\
\text { linguístico, para o entendimento da literatura como manifestação artística e a devida apreciação dessa, para trabalhar o imaginário } \\
\text { do aluno, escrita e oralidade, estratégias de compreensão e interpretação, para formação de leitores, entre outros como análise } \\
\text { crítica e formação cidadã. }\end{array}$ \\
\hline
\end{tabular}

Fonte: Autores (2021).

Algumas respostas $(1,2,6,7$ e 8) ainda defendem a ideia da aquisição de vocabulário e linguagem como um fator importante, mas também percebe-se que os professores acreditam no potencial imaginativo que a leitura de textos literário pode propiciar aos alunos, identificado nas respostas que tratam da compreensão dos alunos ao se identificarem e entrarem em conflito com uma personagem de um livro, por exemplo, refletindo, assim, sobre "sua própria existência", de "aspectos ligados à afetividade e vivências dos alunos, compreensão e interpretação", de "contextualizar os conhecimentos", de "inserir o aluno no mundo da leitura", de desenvolver "a criticidade, a criatividade e que conheçam algumas obras clássicas”, de exigir "mais atenção para formar as possíveis interpretações" e de "trabalhar o imaginário do aluno". O texto literário reconfigura, transforma a realidade e, ao mesmo tempo, aproxima o leitor de sua própria realidade, identificando-o, assim sendo, o discurso literário, "pode estender seus efeitos sobre os sujeitos e suas identidades, as relações sociais e os sistemas de conhecimento e crença. Num mundo de grandes transformações como o nosso, essa é, sem sombra de dúvida, uma questão central” (Fairclough, 2001, p. 12), por isso, segundo os professores, os textos literários servem para transformar e identificar a vida dos leitores.

O questionamento para que serve o texto literário revelou, mais uma vez, a presença de orações mentais cognitivas (1, 2 e 5), por exemplo, "Para compreender ao se identificar", "para trabalhar com aspectos ligados à afetividade" e "objetivo que os alunos desenvolvam a criticidade", mas, também orações mentais desiderativas, que manifestam desejos ou anseios, como na resposta (8), que diz que, a leitura de textos literários "pode servir para movimentar saberes linguístico, além de possibilitar o conhecimento de diversas temáticas sob perspectivas diferentes”. Isso está de acordo com o que foi citado por Fuzer e Cabral (2014, p. 54), pois “os participantes são tipicamente humanos ou coletivos humanos que sentem, pensam, percebem, desejam, por isso, a função léxico-gramatical que desempenham na oração é denominada Experenciador”, dessa forma, revelam suas experiências em sala de aula.

O questionamento de quais competências e habilidades são necessárias para a leitura de textos literários obteve as seguintes respostas: 
Quadro 3 - Na sua percepção, quais competências e habilidades são necessárias para a leitura de textos literários?

\begin{tabular}{|c|c|}
\hline 1 & $\begin{array}{l}\text { Lidar com informações explícitas e implícitas em um texto; podem fazer conexões nos limites do texto ou com seu conhecimento } \\
\text { de mundo; competência de reconhecer a finalidade de um texto e seu tema; podem estabelecer relações entre os elementos do } \\
\text { texto. A leitura possibilita que indivíduos cresçam como seres humanos e profissionalmente e que façam descobertas relacionadas } \\
\text { aos vários elementos que compõem não só seu entorno, mas também os de outras sociedades e culturas. Habilidades de } \\
\text { decodificação; compreensão; interpretação, atenção, memória, concentração. }\end{array}$ \\
\hline 2 & (EF07LP14RS2), (EF67LP06SM-1), EF67LP28, (EF67LP06SM-1) \\
\hline 3 & $\begin{array}{l}\text { Desenvolver a escrita e a oralidade; aperfeiçoar os conhecimentos; auxilia na socialização, entender as relações; partilhar } \\
\text { informações, ideias e experiências em diferentes contextos. }\end{array}$ \\
\hline 4 & $\begin{array}{l}\text { Competências de compreensão da língua como meio de construção de identidades e de apropriação da linguagem escrita. As } \\
\text { habilidades necessárias a essa leitura são a capacidade de se posicionarem e de defenderem um ponto de vista coerente. }\end{array}$ \\
\hline 5 & Eu acho que isso pode ser desenvolvido. Mas ter gosto pela leitura e concentração são importantes. \\
\hline 6 & $\begin{array}{l}\text { Competências: Construção da sintaxe; reconhecimento de funções, aquisição de vocabulário. Habilidades: Ler, conhecer aspectos } \\
\text { culturais de épocas diferentes (em minhas aulas já trabalhei, por exemplo, textos do trovadorismo); identificar elementos } \\
\text { essencialmente dos textos literários (ritmos, rimas, figuras de linguagem, sentidos subjacentes). }\end{array}$ \\
\hline 7 & $\begin{array}{l}\text { Antes de mais nada, gostar de ler. Na sequência, diria que uma boa compreensão do que se lê, ter intertextualidade, conhecimento } \\
\text { de mundo, ser questionador, ter interesse em procurar significado de novas palavras. }\end{array}$ \\
\hline 8 & $\begin{array}{l}\text { Acredito que o aluno precisa ser capaz de observar diferentes aspectos: semântico, sintático e fazer relações com diferentes } \\
\text { conhecimentos e temáticas a partir do texto. }\end{array}$ \\
\hline
\end{tabular}

Fonte: Autores (2021).

As competências e habilidades são estabelecidas pela BNCC e percebe-se que as respostas dos professores aproximamse do que o documento orienta, quanto ao ensino de leitura, por exemplo, o que foi escrito pelos professores $(1,3,4,5,6$ e 7$)$ revelam a importância da leitura para o "conhecimento de mundo", para que os alunos "cresçam como seres humanos", para auxiliar "na socialização, entender as relações; partilhar informações, ideias e experiências em diferentes contextos", a “compreensão da língua como meio de construção de identidades e de apropriação da linguagem escrita", despertar o "gosto pela leitura e concentração", “conhecer aspectos culturais de épocas diferentes" e entender a "intertextualidade”. Uma das Competências Específicas de Língua Portuguesa para o Ensino Fundamental sugere "selecionar textos e livros para leitura integral, de acordo com objetivos, interesses e projetos pessoais (estudo, formação pessoal, entretenimento, pesquisa, trabalho etc.)" (BNCC, 2018, p. 86), corroborando as respostas do questionamento. Da mesma forma, a resposta (2) identificada por (EF07LP14RS2), (EF67LP06SM-1), EF67LP28, (EF67LP06SM-1), revela um profissional já ambientado com a BNCC, pois fez uso dos códigos específicos do documento que definem as competências e habilidades do Ensino Fundamental para responder à questão. Um dos objetivos da experiência com textos literários em sala de aula, segundo a BNCC, é “alcançar seu potencial transformador e humanizador, por isso, é preciso promover a formação de um leitor que não apenas compreenda os sentidos dos textos, mas também que seja capaz de frui-los” (BNCC, 2018, p. 156).

O discurso educacional, presente na BNCC, é dominado por vocabulários relativos às competências e habilidade, os quais se reproduzem nas respostas dos professores. Uma crítica nesse sentido é feita por Fairclough (2001, p. 257), que diz que "o conceito de habilidade é um fator importante ao permitir que duas construções contraditórias dos aprendizes coexistam sem manifestar inconsistência, porque parece ajustar-se tanto a uma visão individualista e subjetiva da aprendizagem como a uma visão objetiva de treinamento", segundo o autor, de um lado as habilidades tem implicações ativas e de outro tem implicações normativas e passivas.

As dificuldades que os professores enfrentam no desenvolvimento de habilidades e competências nos alunos, para que eles leiam textos literários, teve as seguintes respostas: 
Quadro 4 - Quais dificuldades você enfrenta no desenvolvimento de habilidades e competências nos alunos, para que eles leiam textos literários?

\begin{tabular}{|c|l|}
\hline 1 & $\begin{array}{l}\text { Falta de livros, livros velhos e não atrativos aos estudantes, aliada à falta de vontade dos próprios estudantes atraídos por mídias } \\
\text { mais superficiais e chamativas. O não retorno dos livros que vão para as casas para a leitura. Agora com a BNCC foi mais } \\
\text { contemplada a leitura como objeto de apropriação do conhecimento. Muitas vezes trabalhar livros e leitura é visto como matar } \\
\text { aula, como "não querer dar o conteúdo", leia-se gramatical. É preciso também que os professores sintam essa necessidade de } \\
\text { transformação das aulas de aulas de gramática para aulas de linguagem. }\end{array}$ \\
\hline 2 & $\begin{array}{l}\text { Falta de estímulo à leitura e ao estudo em casa, pouco tempo na escola para realizar esta atividade, dificuldade de leitura e } \\
\text { compreensão. }\end{array}$ \\
\hline 3 & $\begin{array}{l}\text { As dificuldades enfrentadas, primeiramente, estão no fato dos alunos não terem o hábito da leitura e, consequentemente, não } \\
\text { conseguirem interpretar e compreender os textos literários. }\end{array}$ \\
\hline 4 & O raro hábito de leitura dos alunos associado à resistência dos mesmos à leitura. \\
\hline 5 & Muitos alunos não querem ler livros com muitas páginas, querem obras mais sucintas. \\
\hline 6 & Eles sentem dificuldade com o vocabulário e com as inversões frasais. \\
\hline 7 & Trazer uma leitura que seja aprazível à grande maioria. \\
\hline 8 & $\begin{array}{l}\text { As dificuldades são diferenciadas de aluno para aluno, variam de acordo com o ano escolar, a instituição, o meio em que o aluno } \\
\text { está inserido. Em geral, a dificuldade que se apresenta inicialmente é a de compreensão relacionada ao pouco tempo dedicado à } \\
\text { leitura por parte do aluno. }\end{array}$ \\
\hline
\end{tabular}

Fonte: Autores (2021).

Percebe-se, de forma geral, que as dificuldades são diversas e todos os professores manifestaram certa angústia nas respostas, por exemplo, sobre a "falta de livros, livros velhos e não atrativos aos estudantes", a "Falta de estímulo à leitura e ao estudo em casa", "os alunos não terem o hábito da leitura", os alunos sentirem "dificuldade com o vocabulário", “Trazer uma leitura que seja aprazível à grande maioria" e a dificuldade que se apresenta inicialmente na "compreensão relacionada ao pouco tempo dedicado à leitura". As repostas (1 e 6) apresentam verbos que revelam processos mentais e geram orações mentais emotivas ou perceptivas, por exemplo, que "os professores sintam essa necessidade de transformação das aulas" e "Eles sentem dificuldade com o vocabulário e com as inversões frasais", esse fenômeno é caraterizado quando o participante sente, pensa, deseja, conhece ou percebe, pois "é um ser consciente ou dotado de consciência” (Fuzer \&; Cabral, 2014, p. 158).

Uma das respostas (1) chama atenção, não para as dificuldades, mas para uma nova perspectiva da BNCC, que segundo o professor, "foi mais contemplada à leitura como objeto de apropriação do conhecimento", no que se refere à "adesão às práticas de leitura" (BNCC, 2018, p. 156).

As estratégias utilizadas pelos professores para superar as dificuldades no desenvolvimento de competências e habilidades de leitura de textos literários são apresentadas nas respostas a seguir: 
Quadro 5 - Quais estratégias você utiliza para superar as dificuldades no desenvolvimento de competências e habilidades de leitura de textos literários?

\begin{tabular}{|c|c|}
\hline 1 & $\begin{array}{l}\text { Eu levo os livros, de uma escola para outra, pego dos meus, faço trocas, levo uma mala vermelha de uma sala para outra, leio uma } \\
\text { parte em voz alta, provoco leitores, oportunizo que façam diferentes formas de me "contarem" o livro lido, desde cartas ao autor, } \\
\text { criar personagens e inserir no livro (co-autoria), tirar um personagem da ficção e incluir na cotidianidade da vida do estudante, } \\
\text { peço para eles construírem booktrailer, mudar a capa pelo programa canva (ou outro), fazerem a galeria dos personagens, uma } \\
\text { entrevista com o autor, ou com um personagem, o que gosta (ou não) em determinado personagem, mudar a ambientação ou o } \\
\text { tempo da narrativa, recitais literários se é poesia. Invento jeitos, adapto outros, e vou indo. E levo os autores, se livros da cidade } \\
\text { para conhecerem os alunos e vice-versa, acontecem interações literárias e humanas incríveis! Adoro sentir os movimentos! Um } \\
\text { livro aberto é sempre uma possibilidade! }\end{array}$ \\
\hline 2 & $\begin{array}{l}\text { Ler com os alunos, várias vezes, contextualizando e acrescentando informações relacionadas ao assunto e que possam interessar } \\
\text { aos alunos.(Isso, nas aulas presenciais) }\end{array}$ \\
\hline 3 & $\begin{array}{l}\text { As estratégias utilizadas para superar as dificuldades ao desenvolver uma atividade de prática de leitura são as oficinas, clubes, } \\
\text { projetos de leitura, oportunizando aos alunos a leitura individual, coletiva, comentada e reflexiva. }\end{array}$ \\
\hline 4 & Tento mostrar o quão importante é a leitura como um todo. E conto com a boa vontade dos alunos! \\
\hline 5 & $\begin{array}{l}\text { Eu tento mostrar a importância de se ler textos literários e procuro selecionar obras que sei que têm temáticas que podem agradar } \\
\text { os alunos. }\end{array}$ \\
\hline 6 & $\begin{array}{l}\text { Geralmente, comento sobre a época em que o texto foi escrito e o que isso influencia em determinadas características da linguagem } \\
\text { que se apresenta. Além disso, faço um glossário com as palavras que geram dúvidas de significado e, em algumas situações, } \\
\text { quando estamos trabalhando com poemas, coloco o texto na ordem sintática direta (sujeito, verbo e complementos), para que } \\
\text { entendem o que se fala e de quem se fala. }\end{array}$ \\
\hline 7 & Uma conversa prévia sobre o tema a ser abordado no texto literário. \\
\hline 8 & $\begin{array}{l}\text { Normalmente, possibilito aos meus alunos maior contato com textos diversos de forma gradual e constante, além de utilizar alguns } \\
\text { recursos tecnológicos para despertar o interesse }\end{array}$ \\
\hline
\end{tabular}

Fonte: Autores (2021).

Ao analisar a última pergunta do questionário identifica-se a disposição dos professores à versatilidade e à inventividade, pois são muito criativos e interessados em motivar seus alunos para a leitura de textos literários. Eles são capazes de levar os próprios livros, leem em "voz alta", criam propostas de atividades diferentes, para incentivar e contextualizar a leitura, fazem “oficinas, clubes, projetos de leitura", criam "glossários com as palavras que geram dúvidas de significado", usam "recursos tecnológicos", etc., ou seja, atitudes que inspiram e servem de exemplo para qualquer professor que trabalhe com a língua portuguesa e o ensino de leitura.

$\mathrm{Na}$ análise da última pergunta, algumas orações materiais aparecem nas respostas $(1,2,4,5$ e 7), definida nas ações e sustentadas nas estratégias utilizadas pelos professores, por exemplo, "Eu levo os livros, de uma escola para outra", "Ler com os alunos", "Tento mostrar o quão importante é a leitura", "Eu tento mostrar a importância de se ler textos literários" e "Uma conversa prévia sobre o tema a ser abordado no texto literário”, por isso, conforme indicado por Fuzer e Cabral (2014, p. 46), “as orações que se desdobram processos materiais como orações de 'fazer e acontecer', por que estabelecem uma quantidade de mudança no fluxo de eventos", assim sendo, demonstrando que os professores são os atores no incentivo e geradores do processo de leitura de textos literários nas suas salas de aula.

\section{Conclusão}

Embora ainda faltem maiores discussões e aprofundamentos, baseados nos estudos da Teoria Social do Discurso de Fairclough e na Gramática Sistêmico-funcional da Língua Portuguesa, pois o presente trabalho é somente parte integrante da dissertação do mestrado, ainda não finalizado, já se pode propor algumas conclusões preliminares, visto que as respostas dos professores para os questionamentos evidenciam algumas crenças.

Assim sendo, percebe-se que todos os professores da pesquisa acreditam que a leitura de textos literários é uma prática importante, pois utilizam-se efetivamente desse tipo de atividade em sala de aula. Revelam-se profissionais já ambientado com a BNCC, pois compreendem as competências e habilidades do ensino de leitura de textos no Ensino Fundamental. Eles concebem 
que a aquisição de vocabulário, a melhora na interpretação e na concentração para o aluno são fatores visíveis e estimulados pelos textos literários.

A capacidade de trabalhar com a arte literária propicia uma comparação entre o mundo da ficção e a própria realidade do aluno. A linguagem inventiva da literatura desperta o imaginário do aluno, revelando não só a fantasia, mas, também, a importância da leitura para conhecer o mundo, a sociedade, a cultura e sua própria língua, respostas que os aproxima dos pensamentos de Fairclough que acredita que a linguagem tem papel importante na mudança social e cultural. Da mesma forma, percebe-se, na maior parte das respostas, a marca de orações mentais, demonstrando que são pessoas que evidenciam suas experiências internas, indicando afeição, cognição, percepção, desejo, que estão ligados à vontade de revelar a importância do mundo da leitura aos seus alunos.

As crenças dos professores nas suas estratégias são inspiradoras, pois todos estão dispostos à versatilidade e à inventividade, são criativos e interessados em motivar seus alunos, isso demonstra a energia dispendida por eles, que é identificada nas orações materiais, pois são os atores no incentivo e geradores do processo de leitura de textos literários nas suas salas de aula. Esses são os professores que desejamos, que provocam espantos nos alunos pelo incentivo à leitura de textos literários.

Sabendo-se que a pesquisa não se encerra aqui, pois é somente uma parte integrante de uma dissertação de mestrado, acredita-se que é fundamental continuar os estudos e planejar futuros projetos de trabalhos, talvez, através das conclusões definidas, possa-se sugerir métodos ou práticas para os professores da rede muncipal que contribuam para o desenvolvimento da leitura de textos literários no Ensino Fundamental das escolas públicas de Santa Maria, no Rio Grande do Sul.

\section{Referências}

Abbagnano, N. (2007). Dicionário de filosofia. Martins Fontes.

Alves, R. (2011). Interpretar e Compreender. Folha de São Paulo.

Bamberger, R. (1991). Como incentivar o hábito de leitura. Ática.

Barcelos, A. M. F., \& Abrahão, M. H. V. (2006). Crenças e ensino de línguas: crenças no professor, no aluno e na formação dos professores. Campinas, Brasil: Pontes.

Bardin, L. (2016). Análise de Conteúdo. Tradução de Luís A. Reto e Augusto Pinheiro. Edições 70.

Fairclough, N. (2001). Discurso e mudança social. Brasília, Brasil: Editora Universidade de Brasília.

Jesus, R. L. L. V. de., \& Magalhães, T. C. (2021). Avaliação da aprendizagem: um olhar à luz das políticas neoliberais implementadas pela Base Nacional Comum Curricular. Research, Society and Development, 10(12), e147101219974. https://doi.org/10.33448/rsd-v10i12.19974.

Silva, M. E. M. da, Menezes, J. M. dos S., \& Farias, S. A. de . (2021). Indicativos de situações didáticas na Base Nacional Comum Curricular: fomentando o protagonismo do aluno . Research, Society and Development, 10(16), e82101623340. https://doi.org/10.33448/rsd-v10i16.23340

Fernandez, A. P. de O., Ramos, M. F. H., Ramos, E. M. L. S., Nina, K. C. F., Silva, S. S. C., \& Pontes, F. A. R. . (2020). Crenças de Eficácia de Professores e Variáveis do Contexto de Ensino. Research, Society and Development, 9(12), e27091210576. https://doi.org/10.33448/rsd-v9i12.10576

Fuzer, C., \& Cabral, S. R. S. (2014). Introdução à gramática sistêmico-funcional em língua portuguesa . Mercado de Letras.

Lajolo, M. (1981). O que é literatura. Brasiliense.

Lima, T. C. S., \& Mioto, R. C. T. (2007). Procedimentos metodológicos na construção do conhecimento científico: a pesquisa bibliográfica. Rev. Katál. 10, $37-$ 45 .

Ministério da Educação. (2017). Base Nacional Comum Curricular. http://basenacionalcomum.mec.gov.br

Morin, E. (2003). Os sete saberes necessários à educação do futuro. Cortez.

Morin, E. (2005). Cabeça bem feita. Bertrand

Novaes, A. (2015).Mutações: A invenção das crenças. Edições Sesc São Paulo. 
Research, Society and Development, v. 11, n. 1, e58511125391, 2022 (CC BY 4.0) | ISSN 2525-3409 | DOI: http://dx.doi.org/10.33448/rsd-v11i1.25391

Nuñes, I. B., \& Santos, F. A. A. (2012). O professor e a formação docente: a criatividade e as crenças educativas onde estão?. Revista HOLOS, 28(2), 148-165. https://www2.ifrn.edu.br/ojs/index.php/HOLOS/article/view/797.

Silva, M. E. M. da, Menezes, J. M. dos S., \& Farias, S. A. de . (2021). Indicativos de situações didáticas na Base Nacional Comum Curricular: fomentando o protagonismo do aluno . Research, Society and Development, 10(16), e82101623340. https://doi.org/10.33448/rsd-v10i16.23340.

Silva, K. de L., \& Fernandes , J. C. da C. . (2020). O ato de ler como instrumento de emancipação humana: importância das práticas de leitura na escola. Research, Society and Development, 9(9), e763997799. https://doi.org/10.33448/rsd-v9i9.7799.

Soares, M. (2003). Letramento: um tema em três gêneros. Autêntica. 